\title{
Article \\ Relationships as a Basis for Safe Drinking Water Provision by Cooperatives in Rural Chile
}

\author{
Claudio Pareja Pineda ${ }^{1, *(1)}$, Norka Fuentes ${ }^{2}$ and Aldo Arriagada ${ }^{2,3}$ \\ 1 Centro de Estudios del Desarrollo Regional y las Políticas Públicas (CEDER), Universidad de Los Lagos, \\ Osorno 5310887, Chile \\ 2 Laboratorio de Limnología, Departamento de Acuicultura y Recursos Agroalimentarios, \\ Universidad de Los Lagos, Osorno 5300800, Chile; norka.fuentes@ulagos.cl (N.F.); \\ aldo.arriagada@ulagos.cl (A.A.) \\ 3 Centro de Investigación en Recursos Naturales y Sustentabilidad (CIRENYS), \\ Universidad Bernardo O'Higgins, Santiago 8370993, Chile \\ * Correspondence: cparejapineda@gmail.com
}

check for updates

Citation: Pareja Pineda, C.; Fuentes, N.; Arriagada, A. Relationships as a Basis for Safe Drinking Water Provision by Cooperatives in Rural Chile. Water 2022, 14, 353. https:// doi.org/10.3390/w14030353

Academic Editors: Andrea Guerrini, Giulia Romano and Elias Dimitriou

Received: 27 October 2021

Accepted: 18 January 2022

Published: 25 January 2022

Publisher's Note: MDPI stays neutral with regard to jurisdictional claims in published maps and institutional affiliations.

Copyright: (C) 2022 by the authors. Licensee MDPI, Basel, Switzerland. This article is an open access article distributed under the terms and conditions of the Creative Commons Attribution (CC BY) license (https:// creativecommons.org/licenses/by/ $4.0 /)$.

\begin{abstract}
While access to drinking water has expanded worldwide, safely managed provision is still a challenge, and rural areas are specially underserved. To provide safe drinking water for these areas, water scholars and international organizations have advocated for community-based organizations or coproduction schemes. The literature often mentions that institutions and people play a key role in the provision of drinking water although the specific mechanisms through which they may affect the process of maintaining good quality water have not been reported yet. The article aims to fill this gap by providing a complex, local view on this process. In Chile, from 1960 onwards, the State has implemented cooperatives to provide for drinking water in rural and small-town areas under a coproduction scheme. In this scheme, the State provides the infrastructure, and the community is responsible for service provision. We analysed the water quality of six of these cooperatives and conducted interviews with water managers and leaders. Our research suggests that formal and informal relationships provide the links and motivation needed for the organizations continuous work. These results highlight how relevant it is to keep in mind the context and the public role of delivering safe drinking water.
\end{abstract}

Keywords: water committees; water governance; interdisciplinary; everyday practices; socio-technical; water supply; Latin America

\section{Introduction}

The recent 2000-2020 UNICEF report on drinking water states that universal, safely managed drinking water is unlikely to be achieved by 2030, with rural areas remaining disproportionally underserved in comparison to urban areas [1]. In rural settings, Statedriven schemes has been dismissed since 1970 as unable to fulfil their objectives [2,3], while market-driven approaches often fail because of the limited opportunities to profit off [4]. For decades, community-driven schemes were presented as an alternative and the most appropriate design, but in recent years, critiques have mounted against this way of working [2,3,5]. Accordingly, a recent advocation of State-community coproduction, where both actors play a significant role in service provision, has flourished [2,6-9]. There is interest in understanding the conditions under which these community organizations, working within a coproduction context, successfully develop accessible, affordable, highquality water services. This article focuses on the latter and provides a nuanced vision of how relationships among actors frame this process.

Coproduction schemes may allow addressing several shortcomings of communitybased water provisioning in rural settings. The ongoing support of the State can deliver the permanent type of financing and training needed for long-term sustainability of these 
systems [2], and also State supervision may help address existing inequality within communities in line with the acknowledgement of the human right to water. On the other hand, when organized in not-for-profit, cooperative-like organizations, users, and citizens may reach greater levels of participation and contribution to the service delivery than in the context of fully public or private service providers [10].

Coproduction arrangements for rural drinking water are long-lived and wide-ranging. In particular for Chile, coproduction schemes serve more than $10 \%$ of the population and over 1.7 million rural and small-town residents [11], making them a substantial and long-serving part of the service provision mix. Further, there are records of communityoperated-State-supported groups since the 1960s, at least in Ecuador [8] and in Chile [12], and from the 1990s in Costa Rica [13] and Nicaragua [14]. Beyond Latin America, there was an extensive review of this type of arrangement in India [2,15]. In the context of rural drinking water, at least in the mentioned Latin American cases, during the implementation phase, coproduction means the State providing for most investment and the community contributing their knowledge and work. During the operation, with the funds collected through a tariff or with voluntary work, users' groups take care of daily management, while the State gives supervision, training, and, in the case of large-scale maintenance, funds.

A specific definition of coproduction is needed to incorporate people and relationships' importance. The practice and idea that the State can deliver services in conjunction with the user communities it serves include a diversity of definitions and practices [16]. From the point of view of development, prominently following the work of Elinor Ostrom, this way of delivering services was proposed as a more efficient and effective way than a Stateonly or private-only delivery [17]. Recent academic views acknowledge that coproducing services would be a way to make up for imperfections of the State [18] or the market [10], reinforcing the need for a more political definition. In this context, local people contribute their resources to remedy the lack of services from the State, and they also contribute their knowledge for successful implementation $[16,18]$. Then, this article follows the definition given by Joshi and Moore [18]: coproduction is "the provision of public services (broadly defined, to include regulation) through regular, long-term relationships between state agencies and organized groups of citizens, where both make substantial resource contributions." It is important to notice that although the literature sets this discussion often in the "global south," a review by the OCED of its member countries argues that due to fiscal pressures, especially after the crisis of 2008, "developed" countries have also embarked on coproduction of services due to lack of resources [19].

Coproduction creates a complex backdrop through an ongoing relationship between communities and the State $[8,20]$; yet, the daily works and the description of specific management functions are seldom mentioned. An exception in line with ideas of focusing on daily practices [21] is one report on the day-to-day work of community organizations that provide water in rural settings in Africa [22] although it did not use the concept of coproduction. In this sense, working with the "flesh and bones" creates a richer picture and a more nuanced comprehension of what works in a specific context [22]. A methodological conclusion from this report is to focus on management functions instead of on management structure to obtain a more accurate depiction of how an organization works [22], an approach this research project follows when studying the water-quality management.

The present study incorporates the details of everyday life and brings infrastructure and people together regarding managing water quality with the aim to shed light on the political aspects of coproduction. The hypothesis behind this research is that people's daily actions frame water management, even specific processes like drinking-water-quality management, in ways not necessarily reflected by formally established norms and standards. Further, this research hypothesizes that it is possible to better understand the processes taking place by focusing on these actions. The project follows the "flesh and bones" by asking those involved in water quality about their actions and perceptions. Yet, the study considers the infrastructure and keeps track of services effectiveness by analysing the quality of delivered water in tandem with social aspects. With this approach, we found 
that good quality of water is indeed interwoven with political aspects. Further, informal relationships seem an important complement to formal rules, especially regarding learning. Finally, our research provides details on how technology affects water quality through the means to make it potable and to study it and on how the environment shapes this process.

From a broader point of view, it is important to acknowledge people's actions because of the political implications of this coproduced service delivery. Coproduction studies tend to focus too much on service effectiveness, leaving aside the political implications of this form of relationship $[8,17,20]$. This narrow focus can leave at least three situations unnoticed. First, a coproduction process initiated by communities in the face of an absentee State can empower those involved [17]. Second, there may be political contestation since there are different possible balances regarding autonomy and dependence in a relationship where the State may condition the organization's work [8]. Third, coproduction could be used strategically to rethink citizen-State relationships by providing meaningful spaces for public participation [20].

Further, beyond governance and coproduction studies, research on water delivery has also highlighted people's role when studying water infrastructure. For example, the relevance of people has been brought forth with the concept of sociotechnical tinkering. These phenomena are defined as "acts [made by people] that produce deviations from the original infrastructural plans and designs" [23]. In this sense, the everyday actions of operators and users are crucial for the system's proper functioning, even if those actions were not foreseen in the original design or are against it. From this point of view, infrastructure is "always-in-the-making" due to decisions individuals make every day [23]. While in the mentioned article, this concept applies to water distribution systems, we will show that the quality process is also always in the making because of operators' learning processes and agency.

An incorporation of the technological and environmental aspects of drinking water provision must complement a focus on people. Coproduction of this service cannot be "reduced to a matter of governance" [24]; people impact the systems through changes in the infrastructure, highlighting the importance of studying the former, too. With this in mind, it is crucial for coproduction studies to include a close view of the flow of water and on the environmental area where the service is delivered [6]. Specifically for water quality, this approach makes sense, as treatment processes should relate to the water quality at the source, and similarly, this water quality relates to the environmental conditions of the stream or aquifer.

From an empirical point of view, in South America, at least four experiences reflect some degree of community involvement in water quality. Two of them have to do with quality management itself. In Peru, during the implementation of a chlorination process in four rural communities, it was found that it was very effective to make discussions with the community and with those who operated the equipment, so community members increased the use of the now-treated water [25]. In Costa Rica, a comparison among three rural drinking-water organizations found that although greater State support and community involvement promoted good performance, financial and time constraints within the community were also crucial to understanding water treatment and management deficits [13].

The other two experiences show how water quality is of interest to communities. In southern Chile, researchers analysed water quality in a rural coastal area where each house obtained the resource from rivers and wells. The study considered the community's active participation, concluding there was great interest among the community for learning about water quality and availability, and it showed the process was effective in facilitating appropriation of the results by community members [26]. A study done in a rural community in northern Argentina concluded that the community's perception of the water quality coming out of its wells was a crucial complementary step to studies of the physical environment. By doing this, public policy related to water uses would be designed more comprehensively [27]. 
The article is organized into six sections. The next one presents the context in which the coproduction scheme in Chile functions and where the studied cooperative-like organizations work. After that, the article follows with a presentation of the methodology and the analysed cases. Next, the results section presents the daily work of the organization as related to water quality. Following, the discussion presents how the results broaden the view of the water quality process as both a technical and a governance issue and identifies some avenues for future research. The conclusion summarizes the main points of the article.

\section{Chilean Context of the Study}

The coproduction scheme for rural drinking water in Chile has a history of more than 60 years. The Chilean State created the rural drinking water committees and cooperatives (Comités y cooperativas de agua potable rural; from now on, APRs) after a loan from the then-recently created Inter-American Development Bank during the 1960s in the context of the U.S.-led Alliance for Progress [28,29]. Although there is a legal distinction between committees and cooperatives in Chile, both are not-for-profit organizations, provide water to members and non-members alike, and work in a cooperative-like way where the member's assembly is the governing body. In 2018, more than 1,800 APRs distributed water to more than 1,700,000 inhabitants throughout the country, reaching more than $10 \%$ of the population [11]. Government estimations indicate that the average APR has 240 house connections [30].

While organizations administer, manage, and maintain the collection, treatment, and distribution systems, several public and private entities have a role in the functioning of this program [31]. First, the Ministry of Public Works (Ministerio de Obras Públicas; hereafter, MOP) provides funding for capital investments. Second, the Health Authority (Autoridad Sanitaria) is the public agency that oversees drinking water quality. Third, as per a contract with the MOP, the Private Urban Water Utilities (Sanitarias) are mandated to provide technical and operational support for the organizations. This research focuses on APRs that are part of the MOP's program, leaving other organizations receiving funding from local or regional governments out of the scope because MOP-related APRs are the ones that continuously receive State support.

Specifically for water quality, the committees and cooperatives are responsible for complying with the guidelines established in the Chilean Standard No. 409/1 of 2005 [30]. Bacteriological analyses are mandatory every other month, while chemical analyses must have a biannual frequency. Private certified laboratories paid by the organization always perform these analyses. Depending on the organization, sampling is made in-house or by a private laboratory. For its part, the regional Health Authority requests and studies these results while performing their own sampling and analysis at least once a year.

For the last 30 years, the State has promoted purification technologies with success but not without difficulties. These technologies usually involve a chlorine-based disinfection unit and a sand-based filtration unit [32]. State evaluations claim the program is successful in improving the population's health by reducing the incidence of diseases associated with poor water quality [28], even if as much as $16 \%$ fail to regularly test the quality of their water [30]. While the overall picture looks promising, a review of 17 APRs in northern Chile found that organizations that operate in small remote localities with less than 500 people presented problems in their water quality [33]. Disinfection processes carry their own risks to water quality [34]; however, to the authors' knowledge, no incidences of these problems have emerged in these organizations.

\section{Materials and Methods}

The research team examined six water organizations in the Osorno province working within the Chilean coproduction scheme for rural drinking water. The Osorno province extends from the Andes to the Pacific, and it is located within $40^{\circ} 19^{\prime} \mathrm{S}$ and $41^{\circ} 00^{\prime} \mathrm{S}$ latitude, at the beginning of the "southern hydrometeorological macroregion" [35]. The climate in this macroregion has an average of $2963 \mathrm{~mm}$ of annual precipitation over an extended 
rainy season [35]. From east to west, the altitude varies from its highest point at the Andes, diminishing through the Chilean central valley, going up again at the Chilean coastal mountain range, and then reaching sea level. In this setting, we selected six APRs within the province, with a longitudinal distribution as shown in Figure 1.

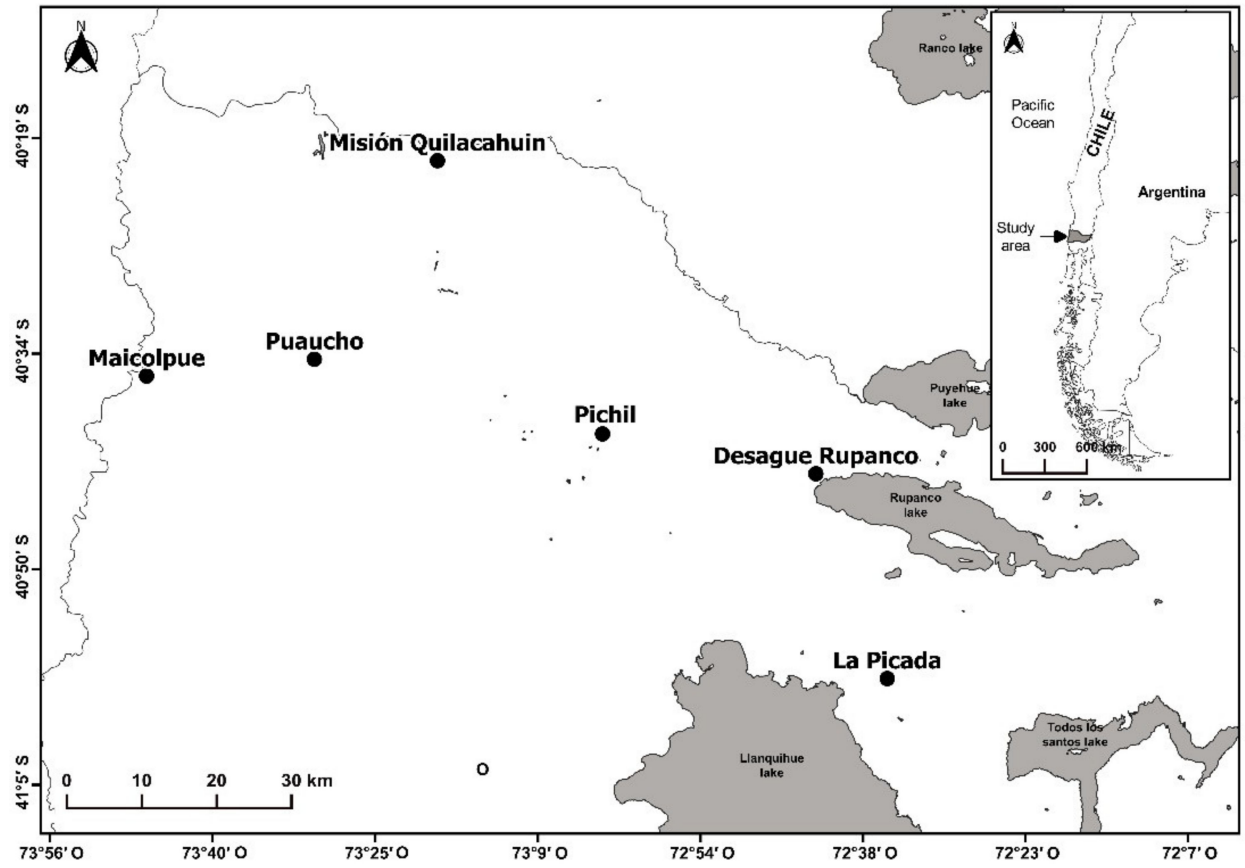

Figure 1. Study area. Six organizations were chosen to incorporate a longitudinal view from west to east in Los Lagos Region of southern Chile.

Further, the selected organizations reflect the diversity existing in this type of system. In this sense, the six organizations have between 68 to 851 household connections, their starting years of operation stretch from 1996 to 2007, and they include both superficial water and groundwater intake. Table 1 shows the specific data for each organization.

Table 1. Operation characteristics of the selected organizations. Organizations vary in the number of household connections, starting year of operation, and type of water intake.

\begin{tabular}{cccc}
\hline Organization & $\begin{array}{c}\text { Number of Household } \\
\text { Connections }\end{array}$ & $\begin{array}{c}\text { Start Year of } \\
\text { Operation }\end{array}$ & Type of Water Intake \\
\hline Maicolpue & 851 & 1996 & Surface (River) \\
Puaucho & 169 & 2000 & Surface (River) \\
Quilacahuín & 146 & 2007 & Groundwater \\
Pichil & 98 & 1993 & Groundwater \\
Desagüe Rupanco & 139 & 2004 & Groundwater \\
La Picada & 68 & 2004 & Groundwater \\
\hline
\end{tabular}

To measure the water quality, we obtained samples from each APR after the chlorination process. This means that the project focused on water quality reaching the tap rather than analysing the water quality of the aquifer or stream at origin. The research team collected two samples: one during summer 2019-2020 and one during winter 2020. A limitation of this approach is that, for each specific date, there was only one round of sampling. To address this issue, when the results were on or beyond the limits of their allowed range, they were complemented with the last State-taken samples in three APRs. The specific aspects to be measured were chosen based on previous State reports that presented the more common pitfalls for these systems [32] although arsenic, boron, and sulphates were only analysed for the summer samples. Table 2 shows a list of the analysed 
elements and their regulatory limits. All parameters were measured in laboratory, using the same methods used by the State, as detailed in the Supplementary Materials: Table S1. Method used to analyse each parameter.

Table 2. Evaluated parameters in the six organizations. The list comprehends physical, chemical, and microbiological aspects based on prior State reports.

\begin{tabular}{ccc}
\hline Parameters & $\begin{array}{c}\text { Type of Possible } \\
\text { Contamination }\end{array}$ & $\begin{array}{c}\text { Limits Based on Chilean } \\
\text { Standard }\end{array}$ \\
\hline Turbidity & Physical & $>4 \mathrm{NTU} \mathbf{H}^{1}$ \\
True colour & Physical & $\leq 20 \mathrm{Pt}-$ Co scale \\
$\mathrm{pH}$ & Chemical & $6.0-8.5$ \\
Iron & Chemical & $\leq 0.3 \mathrm{mg} / \mathrm{L}$ \\
Manganese & Chemical & $\leq 0.1 \mathrm{mg} / \mathrm{L}$ \\
Arsenic & Chemical & $\leq 0.01 \mathrm{mg} / \mathrm{L}$ \\
Nitrates & Chemical & $\leq 50 \mathrm{mg} / \mathrm{L}$ \\
Ammonia & Chemical & $\leq 1.5 \mathrm{mg} / \mathrm{L}$ \\
Boron & Chemical & $\leq 0.5 \mathrm{mg} / \mathrm{L} *$ \\
Chlorides & Chemical & $\leq 400 \mathrm{mg} / \mathrm{L}$ \\
Sulphates & Chemical & $\leq 500 \mathrm{mg} / \mathrm{L}$ \\
Total dissolved solids (TDS) & Chemical & $\leq 1500$ \\
Total coliforms & Microbiological & $<2 \mathrm{MPN} / 100 \mathrm{~mL}$ \\
Escherichia coli & Microbiological & Absence \\
\hline
\end{tabular}

* Based on WHO's guidance, ${ }^{1}$ Nephelometric turbidity units, ${ }^{2}$ Most probable number.

As for the qualitative side of the project, we performed several semi-structured interviews on each APR. Using the same protocol, three interviews were planned for each organization: one for community leaders, one for administrators, and one for technicians/operators. The selection was straightforward in most organizations, as there was only one person in each category. When there was more than one possible interviewee, the most experienced person was selected. In the four smallest organizations, either the community leader or the operator performed the administration's role, so only two interviews were done in these cases. The project involved a total of 14 interviews: eight in the smallest organizations and six in the two larger organizations. Most interviews were done in-person and on-site, except for one in-person but in another place and another by phone due to the Chilean COVID-19 outbreak.

The topics included in the survey were all related to the process of maintaining good water quality. They comprised their assessment of the results and the process, with questions regarding their own definition of good water quality; the actual processes they do for maintaining the water quality, by asking them to list and describe every action they perform to this end; their opinion about the use of cholerine; their relationship with other organizations, companies, and State departments regarding support and supervision, inquiring how and where they look for help and information; and finally, their possibilities for training. The interview included two additional aspects: one set of questions about their context and experience and one final section for the interviewees to make a free final comment. The questions are available in the Supplementary Materials: Table S2. English translation of the Spanish questionnaire applied to each organization. Later, the interview data was analysed and categorized in order to find emerging themes.

These interviews were then complemented with administrative data from the MOP, the Health Authorities, and in-depth interviews with former senior-level public officials within MOP regarding the history of the Chilean rural water program. 


\section{Results}

\subsection{In General, the Organizations Achieve Good Quality}

We found most of the physicochemical parameters of the treated water within the range stablished in the Chilean Standard $N^{\circ}$ 409. Regarding the physical parameters turbidity and colour, samples were within range in four of the organizations. In Puaucho, turbidity exceeded the maximum limit by eight units on the summer sample, while colour was slightly higher by one and four units with respect to the limit on the summer and winter samples, respectively. This situation is similar to what the Health Authority concluded nine months before our sampling [36]. The organization acknowledged the situation and explained that users let the water run before drinking until a proper colour appears. Further, they refer to the forestry industry as one source of the problem and that they are looking into new sources together with the MOP. In Quilacahuín, the turbidity appeared two units above the limit of the norm on the summer sample. The Health Authority examination agrees with ours [37]. It is important to notice that in this case, the State sampling, although earlier, was done very close in time with ours. Figure 2 summarizes our results for the treated water. The actual values for our samplings and the Health Authorities' are presented in the Supplementary Materials: Table S3. Results for every evaluated parameter of our treated-water samples at each APR for the summer samples, Table S4. Results for every evaluated parameter of our treated-water samples at each APR, for the winter samples, and Table S5. Results for samples taken by the Health Authority.

Most of the chemical parameters were within range, but iron, manganese, and ammonia concentrations were above the allowed maximum in two APRs. In Puaucho, iron and manganese were slightly higher than the norm by $0.2 \mathrm{mg} / \mathrm{L}$ and $0.06 \mathrm{mg} / \mathrm{L}$, respectively, on the summer sample, while in the winter samples, the differences were down to $0.1 \mathrm{mg} / \mathrm{L}$ and to $0.05 \mathrm{mg} / \mathrm{L}$, respectively. The Health Authority samples concur with ours regarding iron, but they found manganese within limits [38]. The source of variation in manganese may be explained because it is added in constant intervals regardless of water consumption, as detailed in the following subsection. The manganese showed the same slight difference of $0.06 \mathrm{mg} / \mathrm{L}$ with the norm in Quilacahuín on the summer sample, but the difference increased to $0.66 \mathrm{mg} / \mathrm{L}$ on the winter sample. In the days before State summer sampling, manganese showed a significant difference of $0.47 \mathrm{mg} / \mathrm{L}$, in line with our winter sample [39]. Although the organization never commented on this issue, when provided with the results of our first sampling, they suggested they are still adjusting the addition of manganese. In the same APR, the ammoniac was above the standard by $0.3 \mathrm{mg} / \mathrm{L}$. The Health Authority does not analyse ammonia. The organization conjectures that the elevated ammonia and turbidity are related to a breakage within pipes and declared to be studying the situation.

The microbiological parameters of total coliforms and presence of Escherichia coli showed values following the Chilean standard in all the evaluated APRs. The within-range microbiological values are in line with above-the-minimum values of chlorine.

As for the qualitative evaluation of water quality, water is considered good in all APRs, even if some eventual difficulties arise. Only Puaucho recognized that, in winter, with the first rains, its water quality decreases due to an increase in turbidity. In general, for all organizations, the overall quality was associated with compliance to the norm and to proper chlorination, even though clarity on the specific parameters of the standard was not always present during the interview. In addition, "good water" is associated with an untouched past and a lack of human-made pollution. As risks to water quality, the organization identified that the age of some facilities could translate into breaks and leaks and that commercial activities, such as campgrounds placed upstream, road construction, and agriculture and ranching activities nearby, could be sources of contamination. 

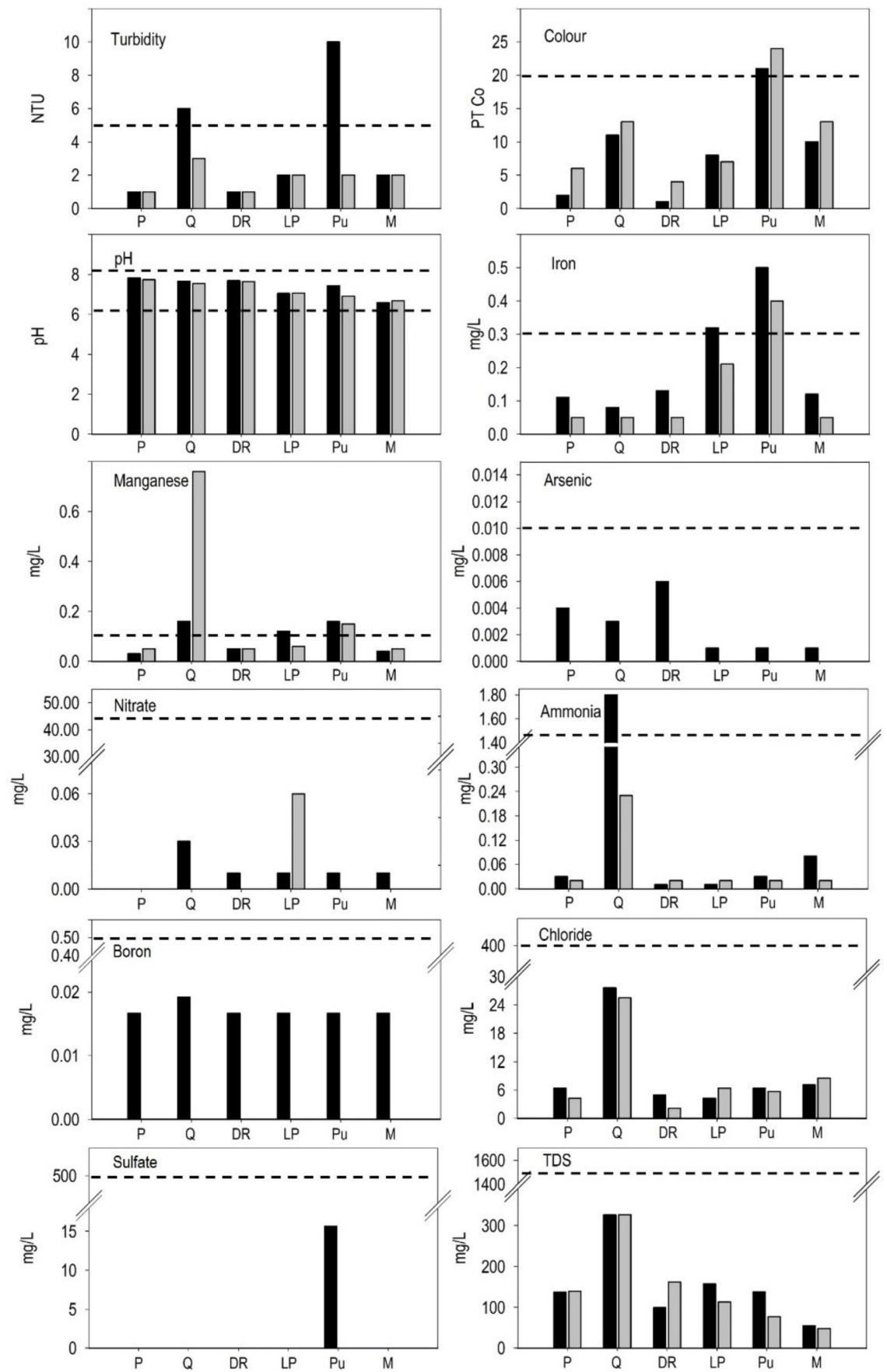

Figure 2. Results for treated water for each organization and its permissible limits according to the national standard except for boron, where the WHO guideline is used. The black and grey bars reflect the values found for the summer and winter samples, respectively. Only two organizations have out-of-range samples. P, Q, DR, LP, Pu and M stand for Pichil, Quilacahuín, Desagüe Rupanco, La Picada, Puaucho and Maicolpue, respectively.

\subsection{The Diversity of Technological Processes and the Incorporation of the Environmental Context}

The quantitative and qualitative evaluations convey that most of the APRs are working within the norms; when studying the actual methods they use to keep the water that way, we found an array of options each APR can take. Every organization agrees in using chlorine to treat the water, as all interviewees indicate that the chlorination process is crucial to maintaining water quality. Moreover, they stated their users agree. This appropriation occurs even when they perceive that the water sources are clean of microorganisms, 
acknowledging that contamination can occur within the system. They are also aware that excess chlorine can be harmful, so they use the minimum and maximum thresholds the norm prescribes as guidance. However, while everyone clearly stated that the water must have chlorine, only in three APRs did they spontaneously indicate the maximum concentration. Daily, the organizations analyse at least two points of the network for chlorine concentration with satisfactory results. Daily, reviews are done with electronic equipment in five of the APRs, while in one, they use a manual system with test tubes.

How organizations add chlorine to the network is similar across them, yet the process has several facets. They use a dosing pump that periodically injects a chlorine solution into the water. Two APRs explicitly detailed that the dosing pump is activated automatically according to consumption, while in two others, they suggested the pump works at regular intervals of time, as they acknowledged differences in chlorine concentration if water consumption is not constant. Operators carry out the process, but in one APR, leaders also know how to do it if the person in charge cannot do it during sick leave or vacation, while in three organizations, a community member can also fill in when the operator cannot prepare the chlorine. There are different types of chlorine used: powder, granulated, or liquid. The decision regarding which type to use relies on experience and the information sellers give to each organization. Four APRs acknowledge that they have had problems with chlorination, in general, due to failures in the dosing pump. On these occasions, and until they resolve the situation, they may do manual chlorination or issue a boil-the-water warning to the community.

Beyond the use of chlorine, committees perform various actions to maintain water quality. The group of interviewees report to (1) clean the filters in the water intake, so they do not become clogged; three organizations do this every day, one every other day, and one when the filter is obviously dirty; (2) clean the water mains by draining the water and letting it fall at the network end, dragging the sediments in the pipes. Two APRs do this at least every 15 days and one every three months. Another does not do it periodically but every time a breakage occurs; (3) hire high-cost contractors to clean the well. Two organizations that reported this process indicated they performed it once a year or when the well-pump needed repair. Equivalently, the two organizations that use surface water perform an annual cleaning on the intake; (4) tank washing. The two organizations mentioning it declare they do it with a frequency of once a year or less.

When analysing which action to take, each person reports balancing diverse factors. The main driver to take a specific action is previous experience and knowledge regarding how to solve a specific problem, like a change in the colour of the water. Besides their experience, each organization considers the inconvenience of cutting off the water supply, historical advice given by authorities, the environmental costs of spilling water, and the financial costs of pumping extra water to do the cleanings.

In addition to the former actions, four APRs do two additional treatments to the water according to the environment where they sit. The first action is that four APRs add permanganate to water to reduce the harmful effects of high iron concentrations. According to their accounts, they started to do this process after suggestions of the supervisory entities, although they do not have clarity as to whether the MOP or the sanitaria suggested it. Permanganate is added to water through dosing pumps, such as those used for cholerine, with concentrations varying between APRs. It is essential to mention that no APR using this chemical has the tools to measure the actual concentration of permanganate or iron present at the end of the treatment process. One interviewee commented his distrust with this process and his doubts about what is worse: an excess of iron or permanganate. Puaucho performed the second action. This APR indicated they used a product to diminish the turbidity due to their use of superficial water, as directed by the authorities.

\subsection{Actors and Relationships for Maintaining a Good Water Quality}

In general, the studied APRs provide good water in physicochemical terms and manage its quality through a diverse, sometimes eclectic, array of processes that consider 
their environment. Nevertheless, we found that these processes happen inside a net of relationships where several actors play an essential part. First, the sanitaria appears as a key player for assistance, while the MOP and private contractors play a secondary role. Second, concerning supervision, the Health Authority is the leader, but the MOP plays a role, too, as it is the one that designs the system in the first place. Third, for learning, peers and general websites are the ones most APRs will reach, as the formal training from the sanitaria seems to have receded. Fourth, to care about the quality, the proximity of everyone involved with the users seems crucial.

Regarding assistance, all organizations relate to the sanitaria, whether in good or bad terms. All APRs mention that they are visited twice to three times a year by the company, and the vast majority indicate that, if they had to ask for help, the sanitaria would be the first one to contact for it. During the visits, the sanitaria resolves accounting, administrative, and technical doubts; performs water sampling; and, occasionally, solves specific problems. The sanitaria also generates some training although "less than before". Despite these positive examples, in five APRs, some interviewees distrust the sanitaria, mainly due to an episode of pollution the company produced in the province's central city and its status as a private company. Likewise, the sanitaria's advice is not always well received because the organizations may perceive it as an administrative requirement without a clear purpose or benefit. For example, an APR mentioned that one time the sanitaria demanded the organization deliver a document in the regional capital by its means, the organization refused, and months later, the situation continued at the time of the interview. Another APR mentioned one occasion when a new worker at the sanitaria suggested a repair, but eventually, the APR had to pay an external technician to solve the problem in a different yet appropriate way.

Organizations point out that the daily relationship with MOP has dwindled, and now, it is focused on expansion projects. Nonetheless, when discussing the recurring turbidity problem related to heavy rain in Puaucho, the organization declared that it could not do anything because it expected the MOP to provide the needed infrastructure. Former senior officers also acknowledged this blurring of responsibilities; one of these functionaries mentioned that the Ministry had to intercede in conflicts between the APRs and the Health Authority regarding water quality on more than one occasion.

As for specific water-quality supervision, the relationship with the Health Authority is constant and affable but not free of conflict. This Authority visits the organization without prior notice, takes water samples, and examines them on site and then in the laboratory. Field results are delivered immediately, while laboratory results are delivered at an upcoming visit if they are within standard or when results are available if they are not. The type of problems the organizations report is telling about how APRs operate and the tangled situations that arise:

- $\quad$ One of the APR commented they stopped using the test tubes that initially the State provided with the project because they were wildly inaccurate. They learned this once the Health Authority fined them; now, they use digital equipment bought with their own resources.

- Another situation involved the Authority taking samples close to filters, which appeared out of range, but a subsequent counter sample presented no problems. The Health Authority concluded that the APR should perform filter cleaning periodically. Notably, the APR refers to this as the first time it was told about this cleaning process.

- In yet another, the Authority issued a fine because, in its opinion, a community septic tank was too close to the water intake. However, it dismissed the fine after the APR appealed because the State had built both facilities, and the Authority had not taken samples before fining the APR. Further, when it did, the samples came out within the range of the norm. Similarly, but with a different outcome, once, the Authority fined an organization for not having a bathroom for employees. Although the APR argued the State had delivered the system without a bathroom, the Authority did not dismiss the fine, and the organization had to build the facility. 
- An additional problem started when the Authority obtained a sample with out-ofrange turbidity inside the local hospital and fined the APR. After performing several counter samples in the network, the Authority concluded that the problem occurred due to poor maintenance of the hospital equipment and dismissed the fine.

- $\quad$ Finally, one APR stated the Authority fined them because an out-of-standard sample appeared in the water intake, i.e., water before treatment. The APR argued that the river water quality was not its responsibility; when the Authority repeated the sampling in the network, it was within range, so it dismissed the fine.

Although the Health Authority indeed gives some fines to the organizations, former senior state officers acknowledge that the State does not have the resources to step in and take over an ailing organization, and although eventually water provision may be halted, the efforts will be to put the organization back on track.

Additionally, five individuals put forward the roles the local public university, where this article's authors belong, can play related to water supervision. On the one hand, all of them commented that this research is helpful because people not familiar with rural drinking water tend to think that these organizations work in a disorderly way and hope it will give greater importance to the systems. On the other hand, one interviewee voiced her eagerness for the university to make a concrete effort to have more accessible prices so that these organizations can analyse their water contracting university's labs. At the moment of the interview, university tariffs were more expensive than private laboratories.

Expertise regarding how to run the systems was gained, predominantly, through practice and through informal ways. In this sense, it is revealing that all interviewees belong to or work in the organization for a long time, exceeding ten years in more than one case. Moreover, several interviewees were associated with the organization since its formation or the construction of the system. There were two informal ways to accelerate the learning process for those newer in this type of cooperative organization: they received the experience from the more knowledgeable people or sought online information on social networks or websites. Finally, the interviewees reported informal links made up of acquaintances who work in other APRs, even from other places in the country, and sellers who also gave them advice. As for formal training, interviewees indicated that years ago, there were numerous opportunities organized mainly by the local sanitaria. While six persons reported that these training addressed water quality, four others explicitly indicated that they had never received formal water-quality training.

Many organizations refered to their public role when asked why it is important to maintain good quality water. Most people readily mentioned that APRs are non-profit organizations with a clear and precise social role. Furthermore, when listing their specific functions, all interviewees stated that theirs is a "full-time $24 / 7$ " job because they always must be ready to correct any problem with the service. Likewise, APRs mentioned the local health centres and schools that use their water as a critical responsibility. In the same vein, all but one person interviewed lived in the territory served by the APR from birth or at least for several years. Finally, when asked for a closing comment, two persons spontaneously referred to the role of APRs in the broader context of water management. One discussed how important it is for the State to intervene in the face of industrial expansion, while the other commented that APRs are an example that could be replicated in urban contexts because of the perceived lower costs and better quality of service for users.

\section{Discussion}

This research aimed to fill the gap regarding how organizations produce good quality water in their day-to-day operation by simultaneously studying the water quality of a group of six of these organizations and the governance involved in this process. The sample included varying sizes, types of water intake, land cover, and geological settings. This research design allowed us to take in different contexts and to provide a complex view of the organizations' diverse processes to improve their water quality. During this research project, we found that formal and informal relationships provide the backbone of 
all the rest. These relationships impacted the learning process of the organization but also their motivation. In this sense, these relationships become institutions as they are "social arrangements_rules, norms — that shape and regulate behaviour and persist" [40].

For example, about learning, acquaintances in other organizations appeared a go-to place for searching new information, or even informal web searches were a way to learn and find solutions to their problems. The relationship with the sanitaria also played a role: while some organizations distrust this utility, others ask them for help. Leaving out a normative evaluation of this, it is natural to think that each side's APRs are receiving different types of information. This finding raises the question of whether a specific type of training may translate in better appropriation than the other.

Further, related to their motivation, several organizations mentioned how important their users were for them. For one matter, they have a clear view of their key users, mostly the local school and health centre. For another, the organization's leadership and workers usually live in the community and drink the same water, making the link and responsibility direct. They understand that an inferior water quality can harm their neighbours and themselves. Acknowledging the public role of water providers should be encouraged in any coproduction scheme. The cooperative-like way of organizing seems appropriate as it allows for users to be simultaneously administrators, and it also involves a broader focus than private profit. A future question could be as follows: can other ways of organizing emphasize the public role of water provision in rural and small-town settings?

The formal relationship with the Health Authority also played a significant role in the motivation and way of working of these organizations. Organizations knew and sometimes experienced the administrative consequences of not following the Authority's guidance. Some organizations also knew how important it is to have their own means to test the water as the Health Authority may not always get it correct at first. In this sense, regular administrative supervision in tandem with acknowledging its public role seems an excellent combination to achieve good quality in the studied organizations.

The diversity in technological processes seemed to not translate in a diversity of water quality results among the organizations, as most of them achieved a good water quality. We interpret this as showing that each organization managed to get to the particular techniques that translate in optimal quality for its specific context. Further studies are needed to identify if some techniques are redundant or inefficiently implemented. In this sense, understanding the management of manganese is also an important focus for future research since the interviews suggest that the Health Authority, the MOP, nor the APRs clearly understand the dosing and the relationship between this mineral and iron.

Two of the organizations had samples with out-of-range values. We found that in one of them existed a blurring of the responsibility to solve this issue bringing forth the importance of relationships again. The role that communities and organizations demand from the State forces the MOP to be part of the solution, even if the APR is the one formally responsible for water quality. Further, the relationship between the APR and its users likely sustains the community's patience while the problem is solved. The other organization with out-of-range samples presented an explanation, the occurrence of a breakage, that suggests that continuous supervision of this type of organization may involve studying the source and the after-filtration water to rule out different situations.

Moreover, two specific minerals were out of range: manganese and iron. Being aware of the lack of details regarding this problem in the Chilean rural drinking water context, we theorize that the source of this contamination is natural and related to the rock formation where the organizations inhabit. This natural contamination suggests that equating the idea of a good water with pristine water can be dangerous if the source water is not entirely understood and regularly studied. Further hydrogeological research is needed to bridge the community's perception and natural sciences' knowledge. Nonetheless, it is significant to mention that the World Health Organization suggests that concentrations of $2 \mathrm{mg} / \mathrm{L}$ for iron and of $0.4 \mathrm{mg} / \mathrm{L}$ for manganese do not represent an immediate health risk [41]; only one of our samples was above these thresholds. Further joint work with the involved 
organization is needed to understand this situation and its possible relationship [41] with the organization's elevated ammonia.

In April 2021, the Government declared the Osorno Province, where the research took place, a "water scarcity" area [42]. While the impact of drought was out of this project's scope, this declaration brings forth the ubiquitous challenges posed by climate change. Drought may decrease the water quality at the source $[43,44]$; in this vein, further research is needed to study the adaptiveness or resilience of the relationships we found against this effect.

Context-specific solutions may be essential to achieve good quality in the water provided in rural and small-town settings even if that translates into a wide array of processes. Plus, the cooperative-like management of the studied organizations, where the served community is directly involved in service provision, seems a proper fit, as this allows the public role of water delivery to emerge naturally. Our research also shows that this type of organization cannot work without the investments and supervision of the State. However, as the controversial relationships with the sanitaria and the Health Authority show, there seems to be a place for organizations' autonomy, as reported elsewhere [8]. All this amounts to the fact that, although the environmental context and technological solutions are important, the roles of actors and institutions are critical to consider.

\section{Conclusions}

If society is to increase the number of people served by safely managed water in rural settings, how governance, particularly relationships, play out on the ground is a key aspect to be considered in tandem with technology and the environment, even if the focus is in a rather specific technology-driven process. The present study of six community-led, cooperative-like organizations working in a coproduction scheme with the State informed that relationships were essential on their daily work regarding water quality. This result suggests that actors are not only significant for the decision-making processes, as the governance literature has extensively reported, but for all aspects of providing water.

In light of our findings, cooperatives or cooperative-like organizations can provide a fertile ground for water delivery. In organizations' own words, leaders and operators are usually available for their communities well beyond regular office hours, and they bring themselves and their networks to work. In this sense, some bricolage exists between how the coproduction scheme prescribes the work and how people understand their public role.

The methodology of this research allowed for a fertile bridge between natural and social science. In this vein, incorporating people's opinions allowed for a thorough apprehension of technological processes and the physicochemical analysis of water granted a counterpoint of people's perception. This bridge was also translated in the researchers whose experience with each other's fields was scarce.

Coproduction schemes where the community is organized as cooperatives can produce safe drinking water when technology, context, and people work together. When implementing this type of scheme, our research suggests that in addition to designing the formal way of working, policymakers should pay attention to people and their relationships. In this sense, we must not forget that as water runs through our bodies, it is people who make safe drinking water run through pipes.

Supplementary Materials: The following are available online at https: / /www.mdpi.com/article / $10.3390 / w 14030353 /$ s1, Table S1. Methods used to analyze each parameter. The used laboratories are accredited according to Chilean standards. The research team received the empty sealed containers, took, cooled, and transported the samples and delivered them to the laboratories within $24 \mathrm{~h}$. An extra column with further references for international readers is also included in the table; Table S2. English translation of the Spanish questionnaire applied to each organization; Table S3. Results for every evaluated parameter of our treated-water samples at each organization, for the summer samples; Table S4. Results for every evaluated parameter of our treated-water samples at each APR, for the winter samples; Table S5. Results for samples taken by the Health Authority. 
Author Contributions: Conceptualization, C.P.P., N.F. and A.A.; methodology, C.P.P., N.F. and A.A.; software, C.P.P. and A.A.; validation, N.F.; formal analysis, C.P.P.; investigation, C.P.P., N.F. and A.A.; resources, N.F.; data curation, C.P.P. and A.A.; writing-original draft preparation, C.P.P., N.F. and A.A.; writing-review and editing, C.P.P.; visualization, A.A.; supervision, N.F.; project administration, N.F.; funding acquisition, N.F. All authors have read and agreed to the published version of the manuscript.

Funding: This research was funded by Universidad de Los Lagos, grants RTI11/19 "Recopilación y análisis de antecedents y diagnóstico preliminar de la calidad del agua de las APR de la provincial de Osorno" and API-3 "Sistema Agroalimentario Sustentable, Cambio Climático y Biodiversidad," and also this work was funded by the National Agency for Research and Development (ANID)/Scholarship Program/Beca Doctorado Nacional/2019-21191149.

Institutional Review Board Statement: Not applicable.

Informed Consent Statement: Not applicable.

Data Availability Statement: No new data were created or analyzed in this study. Data sharing is not applicable to this article.

Acknowledgments: The authors acknowledge the important contribution of the subjects that contributed their time and experience to answer our questions.

Conflicts of Interest: The authors declare no conflict of interest. Although the funders stablished that the study should be done in Los Lagos regions, they had no further role in the design of the study; in the collection, analyses, or interpretation of data; in the writing of the manuscript, or in the decision to publish the results.

\section{References}

1. World Health Organization (WHO); United Nations Children's Fund (UNICEF). Progress on Household Drinking Water, Sanitation and Hygiene 2000-2020: Five Years into the SDGs; World Health Organization (WHO) and the United Nations Children's Fund (UNICEF): Geneva, Switzerland, 2021; ISBN 9789240030848.

2. Hutchings, P. Community Management or Coproduction? The Role of State and Citizens in Rural Water Service Delivery in India. Water Altern. 2018, 11, 357-374.

3. Whaley, L.; Cleaver, F. Can 'Functionality' Save the Community Management Model of Rural Water Supply? Water Resour. Rural Dev. 2017, 9, 56-66. [CrossRef]

4. Bakker, K. The Ambiguity of Community: Debating Alternatives to Private-Sector Provision of Urban Water Supply. Water Altern. 2008, 1, 236-252.

5. Van den Broek, M.; Brown, J. Blueprint for Breakdown? Community Based Management of Rural Groundwater in Uganda. Geoforum 2015, 67, 51-63. [CrossRef]

6. Faldi, G.; Rosati, F.N.; Moretto, L.; Teller, J. A Comprehensive Framework for Analyzing Co-Production of Urban Water and Sanitation Services in the Global South. Water Int. 2019, 44, 886-918. [CrossRef]

7. Mcmillan, R.; Spronk, S.; Caswell, C. Popular Participation, Equity, and Co-Production of Water and Sanitation Services in Caracas, Venezuela. Water Int. 2014, 39, 201-215. [CrossRef]

8. Goodwin, G. The Problem and Promise of Coproduction: Politics, History, and Autonomy. World Dev. 2019, 122, 501-513. [CrossRef]

9. Moretto, L.; Faldi, G.; Ranzato, M.; Rosati, F.N.; Ilito Boozi, J.P.; Teller, J. Challenges of Water and Sanitation Service Co-Production in the Global South. Environ. Urban. 2018, 30, 425-443. [CrossRef]

10. Verschuere, B.; Brandsen, T.; Pestoff, V. Co-Production: The State of the Art in Research and the Future Agenda. Voluntas 2012, 23, 1083-1101. [CrossRef]

11. Ministerio de Obras Públicas (MOP). Desafíos Del Sector Sanitario En Chile Visión Del Sector Rural; Ministerio de Obras Públicas (MOP): Santiago, Chile, 2018.

12. InterAmerican Development Bank (IDB). Water Supply Systems for Rural Towns Ch0098 (74/Tf-Ch); Gobierno de Chile: Santiago, Chile, 1964.

13. Dobbin, K.B.; Sarathy, B. Solving Rural Water Exclusion: Challenges and Limits to Co-Management in Costa Rica. Soc. Nat. Resour. 2015, 28, 388-404. [CrossRef]

14. Romano, S.T. Transforming Rural Water Governance: The Road from Resource Management to Political Activism in Nicaragua; The University of Arizona Press: Tucson, AZ, USA, 2019; ISBN 9780816538072.

15. Hutchings, P.; Franceys, R.; Mekala, S.; Smits, S.; James, A.J. Revisiting the History, Concepts and Typologies of Community Management for Rural Drinking Water Supply in India. Int. J. Water Resour. Dev. 2017, 33, 152-169. [CrossRef]

16. Mitlin, D.; Bartlett, S. Editorial: Co-Production-Key Ideas. Environ. Urban. 2018, 30, 355-366. [CrossRef] 
17. Mitlin, D. With and beyond the State-Co-Production as a Route to Political Influence, Power and Transformation for Grassroots Organizations. Environ. Urban. 2008, 20, 339-360. [CrossRef]

18. Joshi, A.; Moore, M. Institutionalised Co-Production: Unorthodox Public Service Delivery in Challenging Environments. J. Dev. Stud. 2004, 40, 31-49. [CrossRef]

19. Organisation for Economic Co-operation and Development (OECD). Together for Better Public Services: Partnering with Citizens and Civil Society; OECD Publishing: Paris, France, 2011.

20. Lepenies, R.; Hüesker, F.; Beck, S.; Brugnach, M. Discovering the Political Implications of Coproduction in Water Governance Water 2018, 10, 1475. [CrossRef]

21. Truelove, Y.; Cornea, N. Rethinking Urban Environmental and Infrastructural Governance in the Everyday: Perspectives from and of the Global South. Environ. Plan C Polit. Sp. 2021, 39, 231-246. [CrossRef]

22. Whaley, L.; Cleaver, F.; Mwathunga, E. Flesh and Bones: Working with the Grain to Improve Community Management of Water World Dev. 2021, 138, 105286. [CrossRef]

23. Silva-Novoa Sanchez, L.M.; Kemerink-Seyoum, J.S.; Zwarteveen, M. Water Infrastructure Always In-the-Making: Distributing Water and Authority through Thewater Supply Network in Moamba, Mozambique. Water 2019, 11, 1926. [CrossRef]

24. Moretto, L.; Ranzato, M. A Socio-Natural Standpoint to Understand Coproduction of Water, Energy and Waste Services. Urban Res. Pract. 2017, 10, 1-21. [CrossRef]

25. Cruz, M.R.; Arévalo, M.H.; Chamorro, R.F.; Fernández, V.F. Efecto Del Uso de Un Método Artesanal Para El Tratamiento de Agua En Comunidades Rurales de La Región San Martín, Perú. Rev. Peru Med. Exp. Salud Publica 2005, 22, 117-122. [CrossRef]

26. Rivas, Y.; Rivera, D.; Gallardo, R.; Lagos, E.; Yevenes, M.; Zambrano, F.; Mendoza, J. Water Availability, Quality, and Use in Rural Communities of the Chilean Coastal Range. J. Soil Water Conserv. 2020, 75, 75-90. [CrossRef]

27. Sales, R.G.; Guida-Johnson, B. Percepción Ambiental y Producción de Alimentos Para Autoconsumo En Tierras Secas No Irrigadas de Mendoza, Argentina. Rev. Geogr. Norte Gd. 2018, 2018, 109-124. [CrossRef]

28. Dirección de Obras Hidráulicas (DOH). Programa de Agua Potable Rural. 40 Años de Historia, Salud y Desarrollo Para Chile; Ministerio de Obras Públicas: Santiago, Chile, 2005.

29. Nicolas-Artero, C. Las Organizaciones Comunitarias de Agua Potable Rural En América Latina: Un Ejemplo de Economía Substantiva. Polis (Santiago) 2016, 15, 165-189. [CrossRef]

30. Dirección de Presupuestos de Chile (DIPRES). Informe Final. Programa de Infraestructura Hidráulica de Agua Potable Rural; Gobierno de Chile: Santiago, Chile, 2015.

31. Fuster, R.; Donoso, G. Rural Water Management. In Water Policy in Chile; Donoso, G., Ed.; Springer International Publishing: Cham, Switzerland, 2018; pp. 151-163, ISBN 978-3-319-76702-4.

32. Subdirección de Desarrollo Regional y Administrativo (SUBDERE). Estudio de Soluciones Sanitarias Para El Sector Rural; Gobierno de Chile: Santiago, Chile, 2018. Available online: https://digitalcollections.sit.edu/isp_collection/1168 (accessed on 24 October 2021).

33. Kapples, E. La Calidad y Accesibilidad Del Agua Potable Rural Chile: Arica-Parinacota. Indep. Study Proj. Collect. $2011,1168$.

34. Tsitsifli, S.; Kanakoudis, V. Disinfection Impacts to Drinking Water Safety-A Review. Proceedings 2018, 2, 603. [CrossRef]

35. McPhee, J. Hydrological Setting. In Water Policy in Chile; Donoso, G., Ed.; Springer International Publishing: Cham, Switzerland, 2018; pp. 13-23, ISBN 978-3-319-76702-4.

36. Ministerio de Salud (MINSAL). Informe de Ensayo Planta APR Puaucho. Informe 218; Gobierno de Chile: Osorno, Chile, 2019.

37. MINSAL. Informe de Ensayo Planta APR Quilacauin. Informe 1810; Gobierno de Chile: Osorno, Chile, 2019.

38. MINSAL. Informe de Ensayo Planta APR Puaucho. Informe 1850; Gobierno de Chile: Puerto Montt, Chile, 2019.

39. MINSAL. Informe de Ensayo Planta APR Quilacahuin. Informe 9155; Gobierno de Chile: Puerto Montt, Chile, 2019.

40. Merrey, D.J.; Cook, S. Fostering Institutional Creativity at Multiple Levels: Towards Facilitated Institutional Bricolage. Water Altern. 2012, 5, 1-19.

41. WHO. Guidelines for Drinking —Water Quality: Fourth Edition Incorporating the First Addendum; WHO: Geneva, Switzerland, 2017; ISBN 9789241549950.

42. Enríquez, J. Gobierno Decretó “Escasez Hídrica” Para Las Provincias de Osorno, Llanquihue y Chiloé. Radio BioBio 2021. Available online: https:/ / www.biobiochile.cl/noticias/nacional/region-de-los-lagos/2021/04/08/gobierno-decreto-escasezhidrica-para-la-provincia-de-osorno-llanquihue-y-chiloe.shtml (accessed on 24 October 2021).

43. Mosley, L.M. Drought Impacts on the Water Quality of Freshwater Systems; Review and Integration. Earth Sci. Rev. 2015, 140, 203-214. [CrossRef]

44. Peña-Guerrero, M.D.; Nauditt, A.; Muñoz-Robles, C.; Ribbe, L.; Meza, F. Drought Impacts on Water Quality and Potential Implications for Agricultural Production in the Maipo River Basin, Central Chile. Hydrol. Sci. J. 2020, 65, 1005-1021. [CrossRef] 